\title{
Hyperacusis Hacks: Media design ethnographic processing
}

\author{
Luca M. Damiani \\ University of the Arts London \\ London, UK \\ I.damiani@/cc.arts.ac.uk
}

\begin{abstract}
This art-essay is a hybrid format of artwork, case-study and diary reflection. The author shares the first developments of his ethnographic processing of exploring the neurological and auditory condition of hyperacusis he suffers from. Through graphic and media design techniques, he focuses on a specific case study related to his hyper sensorial auditory sense. Using autoethnography, with daily data collection, this work shows and share some aspects of the processing of data from cognitive behaviour therapy (CBT) which the author undertook at SLAM (South London and Maudsley - NHS) in 2018. He started to use a tool for keeping track of his mood daily, keeping track of moments, data, reactions, and patterns. This collection of data created numerical/scientific outputs that the author then explored via coding to create graphics, then connecting to textual diary-reflections via creative writing. This allowed the development of a series of graphics to interpret hyperacusis visually.
\end{abstract}

Hyperacusis. Media design. Sensorial exploration. Autoethnography. Audiology. Neuroscience.

\section{INTRODUCTION}

Hyperacusis is an auditory condition, which brings a higher sensitivity or decreased tolerance to sounds (McKenna, Baguley \& McFerran 2010; Diehl \& Schaette 2015); it is developed when the central auditory processing in the brain perceives noise in an amplified way, leading to pain, oftenextreme discomfort and neurological overload. Like many conditions it will manifest itself in a variety of ways for each person diagnosed with it -different sounds, volumes, pitches, contexts, times, can have a varying impact and experience for each individual. Hyperacusis is a relatively uncommon and often unheard condition - while a sensitivity to sound is less rare, estimates are that hyperacusis affects just one in 50,000 people (ASHA 2015). Its impact can be considerable, debilitating and alienating sufferers from everyday mainstream life, cause extreme fatigue and the associated impact on a person's mental health and wellbeing is significant (British Tinnitus Association 2019). Whilst medical research is on going, a definitive cause of the condition is not absolutely known and although there are various physical and psychological therapies and emerging technologies to help sufferers learn to live and cope, there is currently no straightforward treatment or known cure for hyperacusis, which often lasts indefinitely.

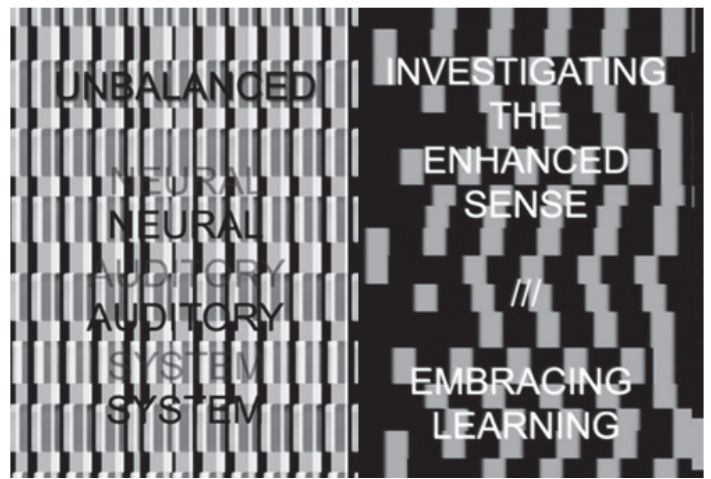

Figure 1: Exploring Hyperacusis Stills, Luca M. Damiani.

Can we visualise the invisible neuro-auditory condition of hyperacusis within contemporary art and design practice? Can we create a series of artworks that could reflect and interpret the hidden patterns of the auditory disorder? In this short piece, I will share some auto-ethnographic data based on my sensorial disorder, investigating hyperacusis via creative writing and media design.

\section{CONTEXT}

The art and design context that I would like to connect to is summarised by Reductionism in Art 
and Brain Science (Kandel 2016). We find the many parallels on scientific data processing and abstract art. The scientist approaches the data, finding patterns and links, narrowing down to smaller significant data to be examined further. The abstract artist extracts elements (such as shapes, or colours, or movement, etc.) from a more figurative image, narrowing down to fewer key elements to examine.

So, within my processing, I will work on this abstraction of key elements, both scientific and artistic. I also want to connect my work to studies about hyperacusis in relation to the arts (Baguley 2016; Baguley 2018); they appear to be underrepresented or almost absent in research and practice in contemporary art and media design. This essay also connects to some of my previous and on-going work around the condition (Damiani 2018, 2019a, 2019c) where I am exploring hyperacusis from a variety of different angles.

\section{METHOD}

I am currently following a variety of therapies for the sensorial disorder: Hearing and Sound Therapy, Cognitive Behaviour Therapy (CBT), and Eye Movement Desensitization and Reprocessing (EMDR). In this art-essay, I share some of the data created during CBT session with the NHS (SLAM) in 2018. I collected info and notes on the condition each day, writing self-observations and responses; this helped for a parallel auto-ethnographic observation (Chang 2009), and this methodological approach became the bridge with my practice as an artist and academic. There are many inner thoughts that the hyper sensorial acoustic disorder brings, and I started to develop auto-ethnographic reflective writing as an output. The first personal and emotional data-responses are collected via words in my diary, which I then analyse, review and build as further pieces of creative writing and poems. An interconnection is created in my poem below, titled Hyper Sensorial Neuro Response.

An almost invisible cause.

\section{Static moving}

Patterns of sounds...invisibly visual.

When it comes hyperacusis hacks.

The flow gets in the rhythm of acoustic disruption.

Then it needs a rebalance of mind and body.

Unbalanced neural auditory system.

Recalling stability.
Recalling a sense of being here or

there. Lost.

Looking in dizziness.

Settled in status of wonder.

On the spectrum channel...it builds up.

Builds up. Builds up.

Until it overflows.

Divergent neuro response.

Altering concepts. Altering sound and reshaping light.

Experiencing insight.

Investigating the enhanced sense.

Narrow down. Analyse. Rationalise.

Ups and downs, touching the deep pain of sound.

Processing in vertigo. Slow slow the mental flow.

Zoning out. Breathe.

Repeat. Breathe.

Repeat.

Empathic acceptance.

Swimming in hybrid fluid.

Invisibly debilitating direction.

Once more with feeling.

In this poem there is a relation to the acoustic and neurological exploration, recoding the analytical processing and interpreting the cognitive response. I also tried to add to the narrative a static, and yet moving and disrupted rhythm, reflecting the vestibular sensation. In addition, I collected data (i.e. trigger response to sound, track-tools numerical outputs, audiological diagrams, diary notes), which I have then interpreted with patterns of ethnographic data that I was able to then analyse in relation to what this sensorial condition brings up in the daily process. Following I show some of these graphics. 


\section{GRAPHICS}

Following from the poems, I then wanted to bridge the textual response to a more visual one, using data from the scientific and technical audiological tests, diagrams, and tools. I recoded the numerical outputs, creating abstracted hacked backgrounds (Damiani 2019b). This process helped me to rationalise further observations, allowing a more distant perspective of an emotional response to the condition. Here I share a composition of graphics, engaging with the poem, recoding it and reshuffling it (as the condition creates disorder) and adding the abstracted disrupted visual background coming from the more scientific data but designed further.

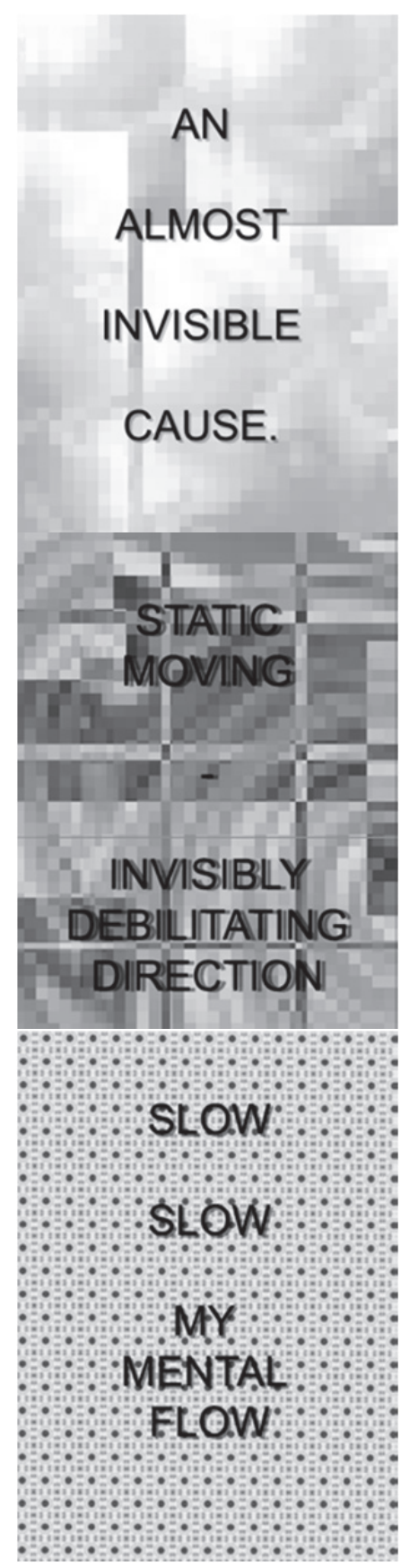

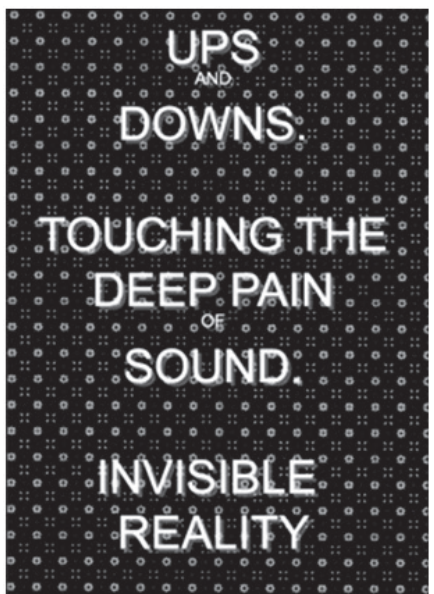
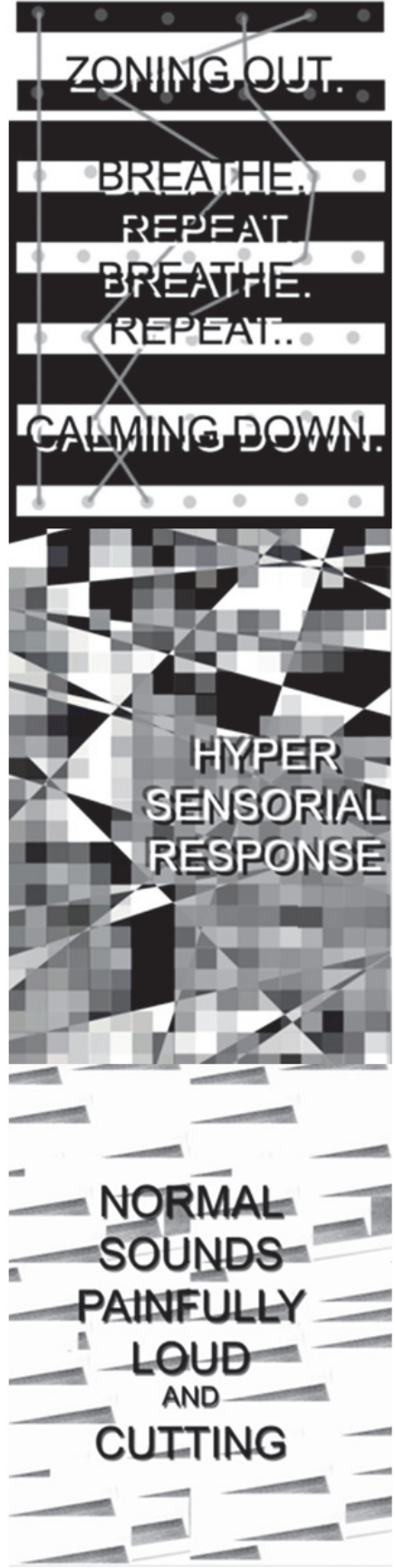


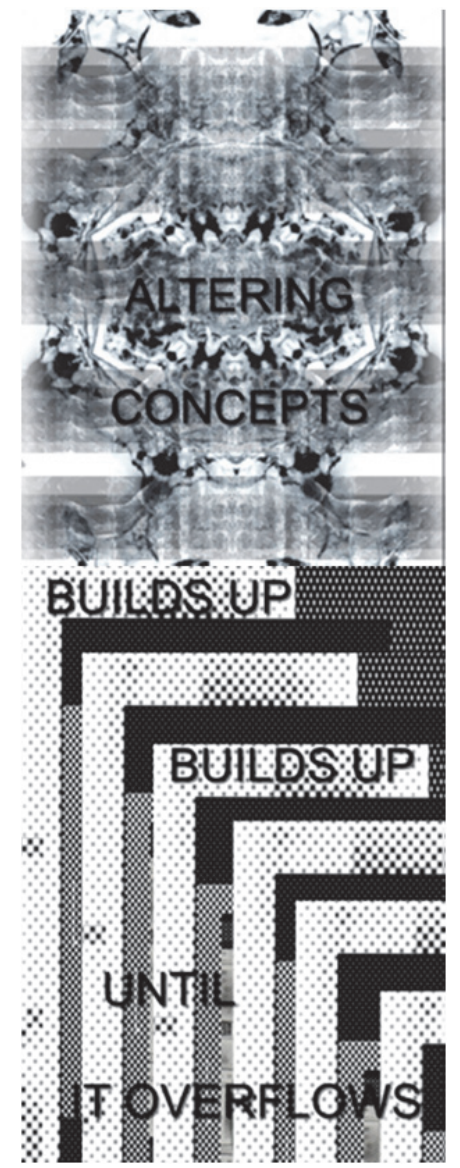

Figure 2: Exploring Hyperacusis Stills, Luca M. Damiani.

\section{ETHNOGRAPHIC VIDEO}

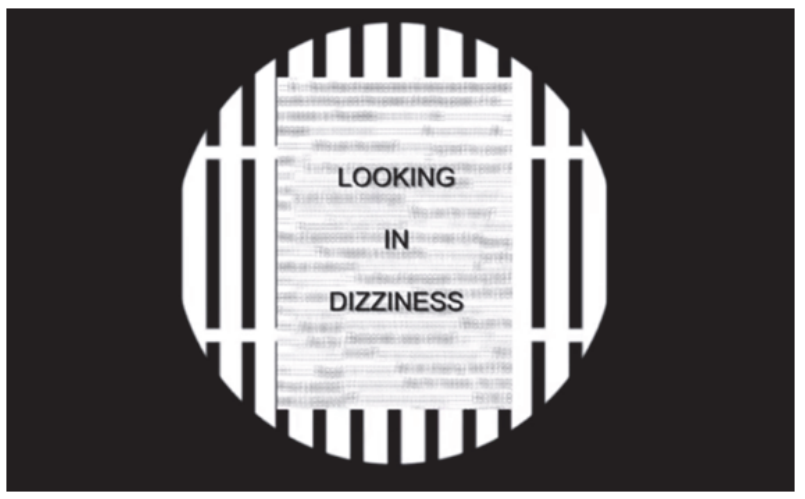

Figure 3: Exploring Hyperacusis Still, Luca M. Damiani.

Combining the poem and the graphics shown earlier, but also further designing my experience, I then create an ethnographic visual podcast. This is sided by a computational filter that conceptually signifies a further disruption of data, outer stimuli, as well as inner voice. In this piece I started to conceptualise more the audiological and scientific data in order to create new graphic visualizations (methodologically and aesthetically connecting to sound), to then over-layer the textual reflection and interpretation. Please follow-up with the video-link below to engage with the video-essay explaining the condition and the processing.

\section{Video-link: https://vimeo.com/304436447}

Password: EVA2019

\section{CONCLUSION AND NEXT STEPS}

In this piece there is an interconnection between artistic practice, acoustic neurological exploration and the recoding of a medical and cognitive aspect. Being analytical in the ethnographic processing of the cognitive responses, I not only explore and share the acoustic and neurological condition, but I experiment with creative visual methods for the processing and analysis of both biological and mental health responses to the condition. From this point, I am aiming to develop this work further, shaping a more in-depth practice-based research to create both artworks and interdisciplinary research outputs in Art and Science.

\section{REFERENCES}

ASHA (2015) American Speech-Language-Hearing Association. http://www. asha.org/uploadedFiles/AIShyperacusis.pdf (retrieved 8 April 2019).

Baguley D. (2016) Tinnitus and Hyperacusis in Literature, Film, and Music. In: Baguley D. M., Fagelson M., (eds) Tinnitus: clinical and research perspectives. Plural Publishing.

Baguley D. (2018) Hearing, tinnitus and hyperacusis in the arts. ENT and Audiology News.

British Tinnitus Association (2019)

http://www.tinnitus.org.uk/hyperacusis (retrieved 8 April 2019).

Chang H. (2009) Autoethnography as Method (Developing Qualitative Inquiry). Routledge.

Damiani L. (2018) Designing the Mind with Hyperacusis and Tinnitus. In: Papadimitriou, I., Rogers, J. and Prescott, S. Artificial Intelligent. V\&A Digital Design.

Damiani L. (2019a) Hyper Sensorial - Human Computed Neurodivergent Poem. Computing Human Interaction.

Damiani L. (2019b) Processing and Designing Hyperacusis and Tinnitus. Art Journal Open.

Damiani L. (2019c) Visualizing my Acoustic Condition: Poem, Graphics and Visual Podcast. In: Hearing and the Medical Humanities. British Medical Journal, Medical Humanities.

Diehl P. and Schaette R. (2015) Abnormal auditory gain in hyperacusis: investigation with a computational model. Frontiers in Neurology.

Kandel E. (2016) Reductionism in Art and Brain Science. Columbia University Press.

McKenna L., Baguley D. and McFerran D. (2010) Living with Tinnitus and Hyperacusis. Sheldon Press. 